\title{
ACORDOS DE INVESTIMENTO E A PROTEÇÃO DE DIREITOS DE PROPRIEDADE INTELECTUAL: RELAÇÃO NATURAL, OU CASAMENTO DE CONVENIÊNCIA? REFLEXÕES SOBRE EXPERIÊNCIAS DO MERCOSUL E DO NAFTA
}

\author{
LOS ACUERDOS DE INVERSIÓN Y LA PROTECCIÓN \\ DE LOS DERECHOS DE PROPIEDAD INTELECTUAL: \\ RELACIÓN NATURAL, O MATRIMONIO DE \\ CONVENIENCIA? REFLEXIONES SOBRE LAS \\ EXPERIENCIAS DEL MERCOSUR Y DE NAFTA
}

Fabrício Bertini Pasquot Polido* Lucas Costa dos Anjos

Resumo: $O$ artigo objetiva investigar o atual contexto analítico sobre a proteção de direitos de propriedade intelectual como investimentos em acordos de investimentos e tratados bilaterais de investimentos (BITs - bilateral investment treaties, em Inglês), tendo como referenciais as experiências de integração regional do NAFTA e MERCOSUL. Será definido o que se entende por propriedade intelectual como investimento, suas principais categorias $e$ as definições usualmente adotadas nos tratados sobre o tema. Em seguida, o artigo examina os diferentes graus de efetividade de instrumentos internacionais como o Protocolo de Colônia e o Protocolo de Buenos Aires no caso do MERCOSUL, relativamente ao tema discutido. Em confronto encontram-se os métodos de solução de controvérsias, os recursos aos quais os Estados têm acesso e as formas de promoção ao investimento no bloco econômico. Finalmente, são analisados casos envolvendo litígios internacionais em matéria de propriedade intelectual e investimentos, como Philip Morris vs. Uruguay, atualmente submetido a procedimento arbitral administrado pelo Centro

\footnotetext{
* Professor Adjunto de Direito Internacional da UFMG e Docente do Corpo Permamente do Programa de Pós-Graduação em Direito da Universidade Federal de Minas Gerais. Doutor em Direito Internacional pela USP. Email: fpolido@ufmg.br

** Mestre em Direito pela Universidade Federal de Minas Gearis.
} 
Internacional de Solução de Controvérsias Relativas a Investimentos (International Centre for Settlement of Investment Disputes - ICSID).

Resumen: Este artículo objetiva investigar el estado actual de la protección de los derechos de propiedad intelectual como las inversiones en los tratados bilaterales de inversión (TBI - Tratados bilaterales de inversión en Inglés) en el Mercosur y el TLC. Se definirá qué se entiende por propiedad intelectual como una inversión, sus principales categorías y los principales ajustes utilizados tratados sobre el tema. Cuestionase la medición de la eficacia de los instrumentos internacionales como el Protocolo de Colonia y el Protocolo de Buenos Aires. Observase los métodos de solución de controversias escogidos, los recursos a los que los Estados tienen acceso y formas de promover la inversión en el bloque económico. Por último, se analizarán casos de controversias internacionales sobre propiedad intelectual e inversiones, como Philip Morris vs. Uruguay, presentado actualmente al arbitraje administrado por el Centro Internacional de Diferencias Relativas a Inversiones (Centro Internacional de Arreglo de Diferencias Relativas a Inversiones - CIADI).

Palavras-chave: Investimentos, Propriedade intelectual, Solução de controvérsias

Palabras clave: Inversiones, Propiedad intelectual, Solución de controversias

\section{INTRODUÇÃO}

As interfaces existentes entre acordos de investimentos e direitos de propriedade intelectual têm sido cada vez mais significativas na atualidade. $\mathrm{O}$ direito internacional dos investimentos e o direito internacional da propriedade intelectual, como áreas de acentuada especificidade e dotadas de linguagens próprias, gradualmente se aproximam, em pontos de convergência material e funcional. Deixam de ser admitidas como disciplinas meramente estanques no universo do direito internacional ou "regimes normativos concorrentes", para justificar objetivos mais amplos de regulação compartilhada no espaço transnacional. Entre eles, exatamente, encontra-se o de proteção jurídica de bens da informação e tecnológicos, a partir de uma retomada, à primeira vista, do caráter privado dos direitos de propriedade intelectual e daqueles direitos subjacentes ou decorrentes de investimentos.

$\mathrm{Na}$ discussão corrente e literatura especializada, o direito internacional dos investimentos apresenta uma racionalidade descritiva fundada nas fontes normativas - primordialmente, tratados bilaterai de investimentos (BITs - bilateral investment treaties, em Inglês) ${ }^{1} 1$

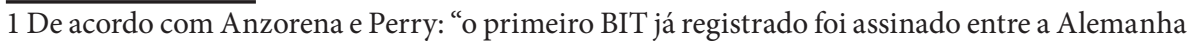


e mecanismos de solução de litígios entre Estados e investidores (em particular a arbitragem). O direito internacional da propriedade intelectual tem se concentrado, por sua vez, na ideia de área específica do direito internacional voltada para a proteção jurídica dos bens da tecnologia e informação, dentro de uma sistemática predominantemente estruturada em tratados multilaterais do final do século XIX, como as Convenções de Berna e Paris ${ }^{2}$ e, mais recentemente, o Acordo TRIPS/OMC ${ }^{3}$. Ambos regimes pareciam muito distantes entre si, sem diálogo sistêmico.

Uma mudança nesse padrão, contudo, passa a ser sentida com muita intensidade. Nas últimas décadas, o que se observou no direito internacional foi a crescente convergência entre as duas áreas, bem como a menção de direitos de propriedade intelectual como categorias de investimentos em $\mathrm{BITs}^{4}$. Essa elevação da incidência de cláusulas

e o Paquistão, em 1959. A Suíça fez o mesmo, firmando um BIT com as Filipinas no mesmo ano. Vários outros países europeus, como a Bélgica, a França, o Reino Unido, a Itália e a Holanda deram seguimento a essa tendência durante os anos 1960 e 1970. Os Estados Unidos iniciaram seu programa de BITs somente em 1981, mas desde então assinaram 47 BITs, além de 20 acordos de livre comércio contendo capítulos que funcionam como BITs, como o Capítulo 11 do Tratado Norte-Americano de Livre Comércio. Tradução livre do trecho: “The first recorded BIT was signed between Germany and Pakistan in 1959. Switzerland followed, entering into a BIT with the Philippines that same year. Several other European countries, such as Belgium, France, the United Kingdom, Italy, and the Netherlands continued this trend during the 1960s and 1970s. The United States began its BIT program only in 1981, but since then it has signed 47 BITs, as well as 20 free trade agreements containing chapters that operate as BITs, such as Chapter 11 of the North American Free Trade Agreement". ANZORENA, C. Ignacio Suarez; PERRY, William K. “The Rise of Bilateral Investment Treaties". In: House Defense Quaterly. 2010, p. 2. [acesso em 23 de fevereiro de 2015]. Disponível em: <http://www.chadbourne.com/files/Publication/ f1898f01-febc-4fba-bb94-87ff36d1bla2/Presentation/PublicationAttachment/8c6065d3-c22f4ale-a187-8c94079e98bc/IDQ-2010-03-SuarezAnzorenaPerry.pdf>

2 "No campo da propriedade intelectual, a criação da União de Paris para a Proteção da Propriedade Industrial de 1883 e da União de Berna para a Proteção das Obras Literárias e Artísticas de 1886, deixou importante legado para o Direito Internacional. [...] Relacionadas pela contingência histórica, as Uniões foram estruturadas pelas normas da Convenção de Paris de 1883 e de Berna de 1886, com o propósito de estabelecer a cooperação técnicoadministrativa entre estados, sem qualquer atribuição de personalidade jurídica de Direito Internacional, e coordenadas pela atuação de órgãos comuns de secretariado". Criticamente, cf. POLIDO, Fabrício B. P. Direito internacional da propriedade intelectual: fundamentos, princípios e desafios. Rio de Janeiro: Renovar, 2013, p. 23.

3 WORLD TRADE ORGANIZATION. Agreement on Trade-Related Aspects of Intellectual Property Rights. April 15, 1994. [acesso em 23 de fevereiro de 2015]. Disponível em: <https:// www.wto.org/english/tratop_e/trips_e/t_agm0_e.htm>

4 No âmbito da União Europeia, o Tratado de Lisboa delegou competência à União Europeia para negociar acordos sobre a proteção de investimentos. Ainda que as estratégias de negociação desses acordos envolva a atuação em âmbitos multilaterais, esse documento expressa claramente que "devido a sua importância econômica global, A União Europeia detém posição favorável para convencer seus parceiros comerciais sobre a necessidade de padrões mais claros e melhores de comércio. O veículo primário para que isso ocorra serão as negociações bilaterais com outros países". Além disso, o mesmo documento define os sistemas de solução de controvérsias preferencialmente elegidos na hipótese de disputas acerca de investimentos que envolvam investimentos, quais sejam, os mecanismos da UNICITRAL, considerados mais transparentes pela Comissão. Tradução livre do trecho: "With its global economic weight, the $\mathrm{EU}$ is in a strong position to convince its trading partners of the need for clearer and better standards. The primary vehicle for this will be through bilateral negotiations with third countries". EUROPEAN COMISSION. Investment Protection and 
de proteção de propriedade intelectual por acordos de investimentos 5 desencadeou consequências intrigantes do ponto de vista da harmonização substantiva e procedimental da propriedade intelectual, como uma espécie de transferência de foro (forum shifting) ${ }^{6}$ em relação às Convenções de Berna e Paris, tratados da Organização Mundial da Propriedade Intelectual e o Acordo TRIPS- Trade Related Aspects of Intellectual Property Rights ${ }^{7}$ para certos conjuntos de acordos regionais e bilaterais.

Além disso, essa recente transformação proporciona maior equiparação entre bens e direitos suscetíveis de proteção por acordos de investimentos (como aqueles textualmente descritos nos instrumentos convencionais) e direitos de propriedade intelectual ${ }^{8}$. Como categoria de

Investor-to-State Dispute Settlement in EU Agreements, november 2013, p. 1. [acesso em 18 de fevereiro de 2015]. Disponível em <http://trade.ec.europa.eu/doclib/docs/2013/november/ tradoc_151916.pdf>

5 Atualmente, a União Europeia negocia acordos bilaterais de investimento com diversos países: Estados Unidos, no âmbito do Acordo de Parceria Transatlântica de Comércio e Investimento (Trans-Atlantic Free Trade Agreement); China; Canadá; Japão; Singapura; Malásia; Vietnã; Tailândia; e Índia, entre outros. As negociações para o estabelecimento de um acordo de livre comércio com o MERCOSUL foram retomadas em 2010, mas ainda encontram dificuldades, sobretudo a respeito dos mecanismos de regulação do comércio (em detrimento de iniciativas de redução tarifária). EUROPEAN COMISSION. The EU's bilateral trade and investment agreements: where are we? December, 2013 [acesso em 18 de fevereiro de 2015]. Disponível em: <http://trade.ec.europa.eu/doclib/docs/2012/november/tradoc_150129.pdf>

6 "Forum shifting pode se referir a diversas dinâmicas distintas, todas destinadas a proporcionar resultados preferenciais por meio de mudanças no "jogo". As partes podem se mover de uma agenda para outra, sair completamente de uma agenda (como os Estados Unidos saindo da UNESCO nos anos 1980), ou atuar em agendas simultâneas em múltiplos fóruns. [...] Países fortes como os Estados Unidos mudam de fóruns para otimizar seu poder e suas vantagens, bem como minimizar a oposição. A agenda de execução de Direitos de Propriedade Intelectual é apenas a mais recente em uma série de mudanças estratégicas de fórum. No entanto, partes mais "fracas", como países em desenvolvimento e a advocacia pública não-governamental (ONGs) também emprega estratégias de forum shifting em seus esforços para remodelar as regras.”.Tradução livre do trecho: “Forum-shifting can refer to several distinct dynamics, all of which are designed to yield preferred results by changing the game. Parties might move an agenda from one forum to another, exit a forum altogether (e.g. the US exiting UNESCO in the 1980s), or pursue agendas simultaneously in multiple forums. Strong states like the U.S. shift forums to optimize their power and advantages and minimize opposition. The IP enforcement agenda is just the latest in a series of strategic forum shifts. Yet "weaker" parties, such as developing countries and public advocacy non-governmental organizations (NGOs), also deploy forum-shifting strategies in their efforts to reshape the rules." SELL, Susan K. Cat and Mouse: Industries', States' and NGOs' Forum - Shifting in the Battle Over Intellectual Property Enforcement. September 1, 2009. [acesso em 23 de fevereiro de 2015]. Disponível em: <http://dx.doi.org/10.2139/ssrn.1466156>

7 WORLD TRADE ORGANIZATION. Agreement on Trade-Related Aspects of Intellectual Property Rights. April 15, 1994. [acesso em 23 de fevereiro de 2015]. Disponível em: <https:// www.wto.org/english/tratop_e/trips_e/t_agm0_e.htm>

8 Afirma-se que esses acordos de investimento corroboram para o aumento de investimento estrangeiro direito nos países, já que garante padrões mais elevados de proteção territorial. No entanto, conforme afirma Umberto Celli Junior: "Não há evidências conclusivas de que Acordos de Investimentos possam levar a um aumento de IED. Estatísticas demonstram que, não obstante muitos países em desenvolvimento terem firmado BITs, eles ainda são destinatários de menos de $1 / 3$ do total do fluxo de IED no mundo. Não constitui, portanto, a participação de acordos multilaterais, regionais ou bilaterais, fator determinante na maior ou menor atratividade de IED. Enquanto em países de menor desenvolvimento relativo da África, por 
investimento, essa qualificação dos direitos de propriedade intelectual confere a seus titulares base legal para reclamações em outros foros que não apenas o Órgão de Solução de Controvérsias da Organização Mundial do Comércio (no quadro do Acordo TRIPS), ou mesmo tribunais estatais para questões envolvendo titularidade, validade de registros, licenças e violação de direitos de propriedade intelectual.

Finalmente, a convergência dos dois regimes - investimentos e propriedade intelectual - também tem corroborado a criação de instâncias jurisdicionais complementares de solução de litígios transnacionais envolvendo direitos de propriedade intelectual, como o recurso das partes a arbitragens internacionais de investimentos, conduzidas segundo as regras e procedimentos do Centro Internacional de Solução de Controvérsias Relativas a Investimentos (International Centre for Settlement of Investment Disputes - ICSID, em Inglês $)^{9}$ e da Comissão das Nações Unidas para o Direito do Comércio Internacional (United Nations Comission on International Trade Law - UNCITRAL, em Inglês) ${ }^{10}$.

Nesse truncado contexto, quais seriam as consequências para os principais atores do direito internacional? Um risco significativo seria a prolação de decisões arbitrais interpretando e aplicando regras sobre direitos de propriedade intelectual totalmente opostas à unidade pretendida pela harmonização substantiva e por padrões mínimos de proteção na sistemática das Convenções de Berna, de Paris e do TRIPS, ou mesmo das leis domésticas de propriedade intelectual ${ }^{11}$. O caso entre

exemplo, a baixa atratividade se deve, dentre outros fatores, à instabilidade política, à ausência de infraestrutura e à reduzida dimensão dos mercados domésticos, em países emergentes, como o Brasil, as oscilações no fluxo de IED decorrem, como precedentemente mencionado, da alta carga tributária, da enorme burocracia, do crédito caro, da má distribuição de renda, do baixo nível de poupança e do ambiente regulatório, dentre outras razões." JUNIOR, Umberto Celli. "O impacto dos acordos de investimentos sobre os Estados-Membros do MERCOSUL". In: Cadernos Prolam/USP. 2005, vol 4, n 6, 2005, p. 94. [acesso em 21 de fevereiro de 2015]. Disponível em: <http://www.revistas.usp.br/prolam/article/view/81786/85094>

9 O regulamento de arbitragem do ICSID entrou em vigor em 15 de outubro de 1966 e é hoje ratificado por 150 Estados. INTERNATIONAL CENTRE FOR SETTLEMENT OF INVESTMENT DISPUTES. Convention on the Settlement of Investment Disputed Between States and Nationals of Other States, October 15, 1966. [acesso em 9 de fevereiro de 2015]. Disponível em: <https://icsid.worldbank.org/apps/ICSIDWEB/icsiddocs/Documents/ ICSID\%20Convention\%20English.pdf>

10 A UNCITRAL especializa-se na reforma, modernização e harmonização das regras de comércio internacional atualmente. Entre seus principais documentos, é possível encontrar convenções, modelos de legislação, guidelines, recomendações práticas, assistência técnica a reformas legislativas, entre outros. As regras de arbitragem da UNCITRAL, adotadas em 1976 e revisadas em 2010, conferem ao Secretário-Geral da Corte Permanente de Arbitragem o papel de nomear autoridades para procedimentos arbitrais e até mesmo atuar como autoridade em procedimentos arbitrais, caso as partes assim o queiram. A Corte Permanente de Arbitragem também oferece apoio administrativo aos procedimentos arbitrais que seguem as diretivas da UNCITRAL. PERMANENT COURT OF ARBITRATION. UNCITRAL Arbitration Rules and the PCA [acesso em 10 de fevereiro de 2015]. Disponível em: <http://www.pca-cpa.org/ showpage.asp?pag_id=1061>

11 Alguns autores afirmam também que o aumento da incidência de BITs e outros acordos regionais diminuiriam a propensão dos Estados a se engajarem nas atuais discussões sobre 
a Philip Morris e o Uruguai ${ }^{12}$, que será melhor explorado ao longo do artigo, retrata bem esses possíveis impactos, já que questiona medidas de saúde pública e regulação de embalagens de cigarro no país sob o pretexto de prejuízos a investimentos em propriedade intelectual no país.

O presente trabalho explora a relação contemporânea entre propriedade intelectual e investimentos, especialmente nos âmbitos do Nafta e do MERCOSUL. No item 1, são analisadas as interações entre acordos bilaterais e plurilaterais de investimento com os direitos de propriedade intelectual. No item 3, analisa-se o atual estado da arte da propriedade intelectual como investimento no contexto dos dois blocos econômicos regionais. $\mathrm{O}$ item 4 explora as propostas, soluções e possibilidades de solução de controvérsias em propriedade intelectual e investimento no Nafta e no MERCOSUL. O item 5 delineia os contornos do contencioso entre Philip Morris e o Uruguai, referente à relação entre propriedade intelectual e investimentos no país, e as considerações finais e as principais conclusões deste estudo.

\section{INTERAÇÕES ENTRE ACORDOS DE INVESTIMENTOS E DIREITOS DE PROPRIEDADE INTELECTUAL}

Existem distintas conformações, escopos e finalidades dos regimes internacionais de proteção dos investimentos, se confrontados com aquelas do regime internacional de proteção dos direitos de propriedade intelectual. Notoriamente, instrumentos de proteção a investimentos, como os BITs:

[...] Se transformaram em ferramentas essenciais na gestão dos riscos políticos de se investir no exterior, porque concedem direitos

\footnotetext{
a liberalização multilateral dos fluxos de comércio e de investimento: "Acordos regionais de comércio também podem prejudicar iniciativas dos governos de pressionar por maior liberalização comercial no âmbito multilateral. Há poucos indícios de que os grandes atores das atuais negociações na OMC tenham mudado suas posições, ou se retirado do sistema multilateral, mesmo quando eles se aproveitam de acordos comerciais regionais. No entanto, como as discussões têm se tornado politicamente difíceis, o risco de que eles abandonem o multilateralismo em favor de acordos regionais 'bons o suficiente' é cada vez mais presente." Tradução livre do trecho: "RTAs can also undercut the incentives of governments to press for further multilateral trade liberalization. There is little evidence that major players in the current WTO negotiations have changed their negotiating positions or retreated from the multilateral process, even as they avail themselves of regional trade deals. However, as the discussions become politically difficult, the risk is ever presente that they will abandon multilateralism in favor of regional agreements that are 'good enough." NEWFARMER, Richard. "Regional Trade Agreements: Designs for Development". In: Trade, Doha and Development: a Window into the Issues. The International Bank for Reconstruction and Development, November 2005. [acesso em 22 de fevereiro de 2015]. Disponível em: <http://citeseerx.ist.psu.edu/viewdoc/dow nload?doi=10.1.1.458.3724\&rep=rep1\&type $=$ pdf\#page $=292>$

12 INTERNATIONAL CENTRE FOR SETTLEMENT OF INVESTMENT DISPUTES. Philip Morris Brand Sàrl (Switzerland), Philip Morris Products S.A. (Switzerland) and Abal Hermanos S.A. (Uruguay) v. Oriental Republic of Uruguay. Case No. ARB/10/7, March 26, 2010. [acesso em 23 de fevereiro de 2015 ]. Disponível em: <https://icsid.worldbank.org/apps/ICSIDWEB/ cases/Pages/casedetail.aspx?CaseNo=ARB/10/7\&tab=PRO>
} 
substanciais a investidores estrangeiros, proporcionam garantias a investimentos contra governos estrangeiros, e normalmente permitem que investidores estrangeiros removam disputas da jurisdição de tribunais locais ${ }^{13}$.

O regime internacional da propriedade intelectual, em seus contornos contemporâneos, ao contrário, busca harmonizar e expandir os padrões substantivos de proteção de direitos de titulares de marcas, de patentes, de direitos de autor, de desenhos, entre outras categorias, dentro de objetivos expansionistas de proteção da propriedade intelectual no contexto pós-TRIPS ${ }^{14}$.

Tratados da propriedade intelectual, como Convenção de Berna sobre Propriedade Artística e Literária de $1886^{15}$, e Convenção de Paris para a Proteção da Propriedade Industrial de $1883^{16}$, não outorgam

13 Tradução livre do trecho: "Bilateral investment treaties (BITs) have become essential tools in managing foreign investment political risks because they grant substantial rights to foreign investors, provide safeguards to investments against foreign governments, and typically enable foreign investors to remove investment disputes from the jurisdiction of local courts". ANZORENA, C. Ignacio Suarez; PERRY, William K. The Rise of Bilateral Investment Treaties. In: House Defense Quaterly, Summer 2010, p. 01. [acesso em 23 de fevereiro de 2015]. Disponível em: <http://www.chadbourne.com/files/Publication/f1898f01-febc-4fba-bb94-87ff36d1b1a2/ Presentation/PublicationAttachment/8c6065d3-c22f-4a1e-a187-8c94079e98bc/IDQ-2010 03-SuarezAnzorenaPerry.pdf>

14 A vinculação da propriedade intelectual a acordos de proteção a investimentos, no entanto, não teve esse efeito. Há fundamentos suficientes para se afirmar que, de fato, essa estratégia apenas levou a um gradual aumento de litigiosidade envolvendo a interface entre propriedade intelectual e investimentos. De acordo com Anzorena e Perry, o aumento da litigiosidade internacional foi considerável: "Até o fim do milênio, mais de 2.000 BITs estavam em vigor, mas mesmo naquela época menos de uma dúzia de disputas eram publicamente conhecidas. Somente após a crise argentina de 2001 que os BITs foram alavancados à linha de frente do direito internacional e da gestão de investimentos com risco político. As medidas adotadas pelo governo da Argentina para lidar com a crise foram contestadas em mais de 40 arbitragens internacionais por investidores estrangeiros, que invocavam os BITs aplicáveis respectivos. $\mathrm{Na}$ última década, mais de 300 casos invocaram BITs, muitos deles envolvendo pedidos de bilhões de dólares. Isso sugere que a utilização efetivas dos BITs aumentou." Tradução livre do trecho: "By the end of the millennium, more than 2,000 BITs were in force, but even then only a handful of disputes were publicly known. It took the Argentine crisis of 2001 to bring BITs truly to the forefront of international law and political-risk investment management. The measures adopted by the government of Argentina to cope with the crisis were challenged in over 40 international arbitrations by foreign investors invoking the respective, applicable BITs. Now, over 300 cases have been filed under BITs during the last decade, many involving claims worth billions of dollars, evidence that awareness of BITs has increased". ANZORENA, C. Ignacio Suarez; PERRY, William K. "The Rise of Bilateral Investment Treaties". In: House Defense Quaterly, Summer 2010, p. 01. [acesso em 23 de fevereiro de 2015]. Disponível em: <http://www.chadbourne.com/files/Publication/f1898f01-febc-4fba-bb94-87ff36d1b1a2/ Presentation/PublicationAttachment/8c6065d3-c22f-4a1e-a187-8c94079e98bc/IDQ-201003-SuarezAnzorenaPerry.pdf>

15 Convenção internalizada no Brasil pelo Decreto no 75.699, de 6 de maio de 1975. BRASIL. Decreto $\mathrm{n}^{\circ} 75.699$, de 6 de maio de 1975. [acesso em 9 de março de 2015 ]. Disponível em: $<$ http://www.planalto.gov.br/ccivil_03/decreto/1970-1979/D75699.htm>

16 Convenção internalizada no Brasil pelo Decreto $\mathrm{n}^{\circ} 75.572$, de 8 de abril de 1975 . BRASIL. Decreto $n^{\circ} 75.572$, de 8 de abril de 1975. [acesso em 9 de março de 2015]. Disponível em: <http:// www.planalto.gov.br/ccivil_03/decreto/1990-1994/D0635.htm> 
imediatamente direitos de propriedade intelectual. A proteção em concreto desses direitos, invocada pelos titulares, é materializada ou instrumentalizada a partir de medidas administrativas e judiciais, propostas perante órgãos estatais e tribunais judiciais. Nesse sentido, o paradigma de proteção ainda é centrado no princípio da territorialidade, em particular nos casos envolvendo direitos de propriedade intelectual dependentes de registros (e.g. patentes, marcas, desenhos industriais). Assim, tecnicamente, cada Estado concede proteção nacional nos termos de sua lei interna, estando vinculado, no entanto, a obrigações assumidas em tratados sobre a matéria, como bem sintetizam aquelas estabelecidas pelo Acordo TRIPS/OMC.

As convenções e tratados da propriedade intelectual são destinados a estabelecer regime normativo de proteção substantiva e procedimental relativo a direitos de autor e conexos, marcas, patentes, desenhos industriais no plano internacional, além de padrões mínimos de proteção a serem adotados pelos Estados, como resultado de obrigações assumidas. A natureza da propriedade intelectual, inclusive, é controvertida ${ }^{17}$, sendo muito distinta daquela de bens móveis e imóveis ou da ideia confusa de "propriedade extraordinária" nos regimes de direito privado, ou que sequer possa justificar a delimitação dos bens passíveis de proteção por meio de "direitos de investimentos", como frequentemente ocorre quanto às definições normativas ou categorias nos acordos de investimentos.

Cada vez mais, titulares litigam contra Estados em tribunais arbitrais internacionais, em disputas que poderiam ser endereçadas pelos tribunais locais ou, havendo violação de obrigações multilaterais do TRIPS, pelo

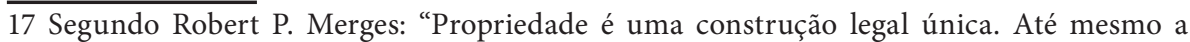
linguagem que utilizamos - o que acadêmicos normalmente denominam "linguajar de propriedade" - é distinta. Poderíamos falar sobre a criação da propriedade como uma 'concessão', uma palavra derivada do termo latino para 'confiar'. O Estado concede a propriedade a um proprietário, que então recebe um pequeno título, uma fagulha do poder do Estado. É esse poder que faz o direito de propriedade um 'bem oponível ao mundo', o que significa duas coisas ao mesmo tempo: primeiramente, que o proprietário pode invocar o poder do Estado para fazer valer esse direito; e, ainda, que não é necessário haver uma relação préexistente entre um proprietário e um terceiro para que o proprietário acione esse terceiro por violar seu direito de propriedade. A única conexão, nesse caso, é que ambos o proprietário e o terceiro estão sujeitos à lei do mesmo Estado." Tradução livre do trecho: "Property is a unique legal construct. Even the language we use - what scholars sometimes call "property talk" - is distinctive. We speak of the creation of property as a "grant," a word derived from the Latin term for "entrust." The state bestows property on an owner, who then carries a small piece, a tiny spark, of the state's power. It is this power that makes a property right "good against the world," which means two things at once: first, that the owner can invoke the power of the state to enforce the right; and second, that there need be no preexisting relationship between an owner and another person for the owner to bring that person to account for violating the property right. The only connection, in such a case, is that both the owner and the other person are subject to the law of the same state." MERGES, Robert P. Justifying intellectual property. Harvard University Press, 2011, p. 292. [acesso em 11 de março de 2015]. Disponível em: <http://denning.law.ox.ac.uk/news/events_files/JIP_-_Chapter_10_-_Conclusion_-_ June_2011.pdf> 
Órgão de Solução de Controvérsias da OMC. Para autores como William W. Park e Guillermo Aguilar Alvarez, os últimos anos contaram até mesmo com maior participação de países em desenvolvimento nos processos de arbitragem de disputas sobre investimentos:

Países em desenvolvimento perceberam que, quanto maior o risco, maior o custo de se investir. Mecanismos de proteção pouco confiáveis tendem a diminuir a cooperação econômica em geral, ainda que em detrimento da grande necessidade de esses países receberam capital estrangeiro para se desenvolverem, Devido ao fato de que a arbitragem promove o respeito a negociações implícitas entre investidores e o país anfitrião desses investimentos, ela passou a ser contemplada como um mecanismo sensato de política econômica internacional ${ }^{18}$.

O tema examinado também é de interface entre investimentos e direitos de propriedade intelectual nos sistemas domésticos, bilaterais, regionais e multilaterais. Do ponto de vista das fontes do direito internacional da propriedade intelectual e do direito internacional dos investimentos, parece existir autêntico caso de colisão de regimes normativos, a ponto de justificar a ideia dos regimes autônomos ("selfcontained regimes") e jurisdições concorrentes, na qual se ancora mesmo uma dada retórica na doutrina jusinternacionalista ${ }^{19}$.

A inclusão de cláusulas concernentes à proteção de direitos de propriedade intelectual admitidos como ativos de investimentos (a exemplo de BITs e do Protocolo de Colônia ${ }^{20}$ do MERCOSUL) está em maior evidência na atualidade. Ao lado, portanto, de medidas administrativas e judiciais adotadas por titulares nos Estados nos quais reclamam a proteção jurídica de direitos de propriedade intelectual, o recurso à arbitragem internacional de investimentos (arbitragem Estadoinvestidor) representa alternativa a satisfazer estratégias ofensivas no campo da propriedade intelectual.

18 Tradução livre do trecho: "Developing countries also came to realize that the greater the risk, the higher the cost of investment. Untrustworthy enforcement mechanisms tend to chill cross-border economic cooperation to the detriment of those countries that depend most on foreign capital for development. To the extent that arbitration promotes respect for implicit bargains between investor and host country, it came to commend itself to developing countries as a matter of sound international economic policy". ALVAREZ, Guillermo Aguilar, and PARK, William W. "The New Face of Investment Arbitration: NAFTA Chapter 11". Yale J. Int'l L. 28. 2003, $\mathrm{n}^{\circ} 365$, p. 703. [acessado em 18 de fevereiro de 2015]. Disponível em: <http:// www.law.yale.edu/documents/pdf/sela/Chapter_IV-D-2_Investment_Arbitration.pdf>

19 Cf. por exemplo, SIMMA, Bruno; PULKOWSKI, Dirk. "Of planets and the universe: selfcontained regimes in international law". European Journal of International Law. 2006, vol 17, $\mathrm{n}^{\circ}$ 3, p. 483-529; TEUBNER, Gunther; FISCHER-LESCANO, Andreas. "Regime-collisions: the vain search for legal unity in the fragmentation of global law". Michigan Journal of International Law. 2004, vol 25, n 4, p. 999-1046.

20 MERCOSUL. Protocolo de Colônia para a promoção e proteção recíproca de investimentos no MERCOSUL (intrazona). 17 de janeiro de 1994. [acesso em 18 de fevereiro de 2015]. Disponível em: <http://www.cvm.gov.br/port/relinter/MERCOSUL/coloni-p.asp> 
Trata-se de reforço procedimental, portanto, em nível de contencioso internacional, que busca maximizar a proteção de direitos de titulares (particularmente empresas). Ele permite maior distanciamento dos modelos convencionais de controle judicial sobre litígios envolvendo propriedade intelectual por tribunais estatais e órgãos de solução de controvérsias com jurisdição a ser exercida decorrente de acordos multilaterais (como seria o caso do Acordo TRIPS/OMC especificamente).

A racionalidade de acordos de proteção recíproca ou tratados bilaterais de investimentos, todavia, é distinta daquela dos tratados relativos à propriedade intelectual. Os primeiros são especificamente destinados a proteger direitos de propriedade sobre bens e ativos, e outros dela derivados, contra a interferência governamental. Buscam endereçar situações de discriminação, tratamento não equitativo em relação a indivíduos e empresas na esfera da titularidade e exercício de direitos decorrentes de relações jurídicas de investimentos.

Essa constatação é corroborada pelas distintas estruturas e funções da disciplina dos investimentos e a da propriedade intelectual. O direito dos investimentos confere aos titulares-investidores mecanismos substantivos e procedimentais de proteção dos bens evolvendo atividades de investimento em Estados receptores. Os direitos de propriedade intelectual, por seu turno, conferem direitos de exclusivo aos titulares. Especificamente em relação ao Acordo TRIPS, são estabelecidas obrigações, aos Membros da OMC de implementar, em seus respectivos sistemas domésticos, os padrões mínimos de proteção da propriedade intelectual ali previstos e mecanismos de aplicação da proteção (respectivamente na Parte II e III do Acordo) ${ }^{21}$.

Nesse contexto, é importante verificar a forma como a proteção à propriedade intelectual tem sido tratada em acordos de livre-comércio e de incentivos ou promoção recíproca de investimentos. No contexto do Acordo TRIPS/OMC, em seu artigo 1.1, é concedida aos membros liberdade para adotar em seus territórios padrões mais abrangentes de proteção à propriedade intelectual ${ }^{22}$. Ou seja, o Acordo representa um "mínimo protetivo", que pode ser suplementado por outros instrumentos

21 Sobre isso, cf. KLOPSCHINSKI, Simon. Der Schutzgeistigen Eigentums durchvölkerrechtliche Investitionsverträge. Berlin: C.Heymanns, 2011, especialmente Cap.2; POLIDO, Fabrício B. P. Direito Internacional da Propriedade Intelectual. Rio de Janeiro: Renovar, 2013, p. 184 e ss, 286 e MERCURIO, Bryan. "Awakening the Sleeping Giant: intellectual property rights in international investment agreements". Journal of International Economic Law. 2012, vol 15, $\mathrm{n}^{\circ} 3$, p. 871 .

22 Artigo 1.1 do Acordo TRIPS: "Members shall give effect to the provisions of this Agreement. Members may, but shall not be obliged to, implement in their law more extensive protection than is required by this Agreement, provided that such protection does not contravene the provisions of this Agreement. Members shall be free to determine the appropriate method of implementing the provisions of this Agreement within their own legal system and practice." WORLD TRADE ORGANIZATION. Agreement on Trade-Related Aspects of Intellectual Property Rights. April 15, 1994. [acesso em 23 de fevereiro de 2015]. Disponível em: <https:// www.wto.org/english/tratop_e/trips_e/t_agm0_e.htm> 
normativos, sejam eles de alcance bilateral ou multilateral.

A possibilidade de estender os padrões de proteção tem acarretado condutas de 'forum shifting' por determinados Estados, que passam, em virtude de maior poder de barganha, a incluir a agenda expansionista dos direitos de propriedade intelectual em acordos conexos, como de proteção a investimentos. Essa mudança de foro afeta diretamente os meios de solução de controvérsia eleitos, bem como a forma de utilização dos dispositivos por Estados e outros atores das relações econômicas internacionais. Nesse contexto, concorrem três alternativas jurisdicionais e contenciosas: o Órgão de Solução de Controvérsias da OMC, responsável por dirimir questões referentes ao TRIPS; tribunais internos dos Estados; e tribunais arbitrais internacionais, como o ICSID.

Para fins de delimitação do objeto deste artigo e aprofundamento da análise, a propriedade intelectual foi examinada no âmbito de acordos do NAFTA e do MERCOSUL, nos quais essas três alternativas jurisdicionais e contenciosas são relevantes. No contexto desses blocos econômicos regionais, quais seriam os instrumentos adequados de relativização e proteção dos direitos de propriedade intelectual?

\section{PROPRIEDADE INTELECTUAL NOS ACORDOS DO NAFTA E DO MERCOSUL}

Alguns tratados regionais fazem menção específica à propriedade intelectual como uma espécie de investimento. Acordos de livre-comércio e de integração regional, como o Tratado Norte-Americano de Livre Comércio (North American Free Trade Agreement - NAFTA, em Inglês), assim como atos e protocolos do MERCOSUL, por exemplo, possuem definições caracterizando direitos de propriedade intelectual como espécies de investimentos. Tratados bilaterais de proteção a investimentos também adotam a mesma técnica, além de elegerem métodos de solução de controvérsias envolvendo temas de propriedade intelectual.

Com o objetivo de comparar esses instrumentos e facilitar a visualização dessas definições, o quadro a seguir ilustra algumas situações: 


\begin{tabular}{|c|c|c|c|}
\hline Acordo & Vigência & $\begin{array}{l}\text { Alcance } \\
\text { territorial }\end{array}$ & Definição de propriedade intelectual \\
\hline $\begin{array}{l}\text { Protocolo } \\
\text { de Colônia } \\
\text { (1994) }\end{array}$ & $\begin{array}{lr}\text { Ainda } & \text { não } \\
\text { está } & \text { em } \\
\text { vigor } & \end{array}$ & $\begin{array}{l}\text { M e m b r o s } \\
\text { do Mercosul } \\
\text { (A rge } \mathrm{n} \text { i i a a, } \\
\text { Brasil, Paraguai, } \\
\text { Uruguai } \\
\text { Venezuela) }\end{array}$ & $\begin{array}{l}\text { Artigo } 1 \text { - O termo "investimento" designa, todo tipo de ativo investido direta ou indiretamente por } \\
\text { investidores de uma das Partes Contratantes no território de outra Parte Contratante, em conformidade } \\
\text { com as leis e a regulamentação dessa última. Inclui, em particular, ainda que não exclusivamente: } \\
\text { d) direitos de propriedade intelectual ou imaterial, incluindo, direitos de autor e propriedade } \\
\text { industrial tais como patentes, desenhos industriais, marcas, nomes comerciais, procedimentos } \\
\text { técnicos, know how e fundo de comércio }{ }^{23} \text {; }\end{array}$ \\
\hline $\begin{array}{l}\text { Protocolo } \\
\text { de } \quad \text { Buenos } \\
\text { Aires (1994) }\end{array}$ & $\begin{array}{lr}\text { Ainda } & \text { não } \\
\text { está } & \text { em } \\
\text { vigor } & \end{array}$ & $\begin{array}{l}\text { M e m b r o s } \\
\text { do Mercosul } \\
(\text { A r g e } \mathrm{n} \text { i } \mathrm{n} \text { a, } \\
\text { Brasil, Paraguai, } \\
\text { Uruguai } \\
\text { Venezuela) }\end{array}$ & $\begin{array}{l}1 \text { - O termo "investimento" designará, em conformidade com as leis e as regulamentações do Estado- } \\
\text { Parte em cujo território o investimento for efetuado, todo tipo de ativo direta ou indiretamente investido } \\
\text { por investidores de um Terceiro Estado no território do Estado-Parte, de acordo com a legislação } \\
\text { deste. Incluirá, em particular, ainda que não exclusivamente: d) direitos de propriedade intelectual } \\
\text { ou imaterial, incluindo, em especial, direitos autorais, patentes, desenhos industriais, marcas, nomes } \\
\text { comerciais, procedimentos técnicos, know how e fundo de comércio }{ }^{24} \text {; }\end{array}$ \\
\hline 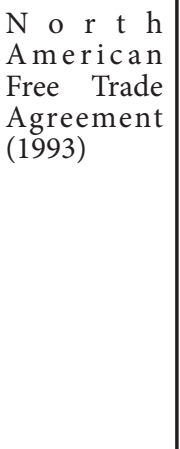 & $\begin{array}{l}\text { Em vigor } \\
\text { d e s d e } \\
\text { janeiro de } \\
1994\end{array}$ & $\begin{array}{l}\text { Membros do } \\
\text { NAFTA (Canadá, } \\
\text { Estados Unidos e } \\
\text { México) }\end{array}$ & $\begin{array}{l}\text { Chapter Eleven: Investments, Section C, Definitions: investment means: (g) real estate or other property, } \\
\text { tangible or intangible, acquired in the expectation or used for the purpose of economic benefit or other } \\
\text { business purposes. } \\
\text { Chapter Seventeen, Intellectual Property, Article 1701, Nature and scope of obligations: 1. Each Party shall } \\
\text { provide in its territory to the nationals of another Party adequate and effective protection and enforcement } \\
\text { of intellectual property rights, while ensuring that measures to enforce intellectual property rights do } \\
\text { not themselves become barriers to legitimate trade 2. To provide adequate and effective protection and } \\
\text { enforcement of intellectual property rights, each Party shall, at a minimum, give effect to this Chapter } \\
\text { and to the substantive provisions of: (a) the Geneva Convention for the Protection of Producers of } \\
\text { Phonograms Against Unauthorized Duplication of their Phonograms, } 1971 \text { (Geneva Convention); (b) } \\
\text { the Berne Convention for the Protection of Literary and Artistic Works, 1971 (Berne Convention); (c) } \\
\text { the Paris Convention for the Protection of Industrial Property, } 1967 \text { (Paris Convention); and (d) the } \\
\text { International Convention for the Protection of New Varieties of Plants, } 1978 \text { (UPOV Convention), or } \\
\text { the nternational Convention for the Protection of New Varieties of Plants, } 1991 \text { (UPOV Convention) }{ }^{25} \text {. }\end{array}$ \\
\hline
\end{tabular}

Fonte: Elaboração própria dos autores - Quadro comparativo de tratados do MERCOSUL

23 MERCOSUL. Protocolo de Colônia. 17 de janeiro de 1994. [acesso em 18 de fevereiro de 2015]. Disponível em: <http://www.cvm.gov.br/port/ relinter/mercosul/coloni-p.asp> 
No MERCOSUL, ambos os instrumentos que lidam com o tema, o Protocolo de Colônia e o Protocolo de Buenos Aires, ainda não estão em vigor, com pendência de ratificação e depósito em diversos Estadosmembros $^{26}$. Segundo José Augusto Fontoura Costa:

Dentre os países do MERCOSUL o Brasil é a única exceção no que se refere à ratificação desses acordos. Embora este país tenha firmado 14 acordos nos anos 90, não chegou a ratificar nenhum destes. A Argentina tem 58 acordos firmados, dos quais 53 estão em vigor. Tanto o Paraguai, quanto o Uruguai têm, cada um, mais de vinte TBIs em vigor. Deste modo, pode-se afirmar que o tratamento multilateral dos investimentos estrangeiros é bastante limitado, abrangendo um importante sistema de solução de controvérsias (Cisdi), uma agência de seguros contra riscos políticos (Miga) e algumas regras sobre circulação de capitais nos Artigos do FMI. No âmbito regional, embora em outras regiões integradas, como NAFTA, CAFTA e EU sejam comuns sistemas de liberalização e proteção de investimentos, o MERCOSUL teve pouco ímpeto para liberalizar e proteger investimentos, tanto no que se refere aos originários da própria região (Protocolo de Colônia de 1994), quanto na oferta unilateral de proteção (Protocolo de Buenos Aires de 1994) ${ }^{27}$.

Uma das razões para que essas ratificações não tenham sido concluídas até hoje é que os dispositivos dos Protocolos de Colônia e de Buenos Aires limitariam, em demasia de esses Estados -adotarem medidas de regulação internas e políticas de investimento. Igualmente, permitiriam que investidores privados questionassem, em juízo, Estados que contrariassem os termos desses acordos ${ }^{28}$.

Não há instrumentos que elevam os padrões mínimos de proteção do Acordo TRIPS no âmbito do bloco econômico sul-americano. Os acordos sobre o tema dizem respeito a normas de harmonização, como

24 MERCOSUL. Protocolo sobre promoção e proteção de investimentos provenientes de Estados não-membros do Mercosul. 05 de agosto de 1994. [acesso em 23 de fevereiro de 2015]. Disponível em: <http://www.cvm.gov.br/port/relinter/mercosul/buenos-p.asp >

25 NAFTA. North American Free Trade Agreement. 10 de janeiro de 1994. [acesso em 18 de fevereiro de 2015]. Disponível em: <https://www.nafta-sec-alena.org/Home/Legal-Texts/NorthAmerican-Free-Trade-Agreement $>$

26 MERCOSUL. Estado de ratificaciones y vigências de tratados y protocolos del Mercosur y Estados asociados. [acesso em 23 de fevereiro de 2015]. Disponível em: <http://www.mre.gov. py/v1/Adjuntos/mercosur/mercosurprincipal.htm>

27 COSTA, José Augusto Fontoura. "Proteção e promoção do investimento estrangeiro no MERCOSUL uma ferramenta para a implementação de um bom clima de investimentos?". In: Revista Brasileira de Política Internacional. 2006, vol 49, nº. 2. [acesso em 11 de março de 2015]. Disponível em: <http://www.scielo.br/scielo. php?script=sci_arttext\&pid=S0034-73292006000200004\&lng=en\&nrm=iso >

28 TORRES, Igor Gonçalves. "Acordos de livre comércio, desnacionalização e sistemas financeiros : os casos do Brasil, Chile e México". [Tese de Doutorado em História]. Brasília: Universidade de Brasília, 2006. p. 94. [acesso em 11 de março de 2015]. Disponível em: <http:// repositorio.unb.br/bitstream/10482/7615/1/2006_igor_torres.pdf> 
o Protocolo de Harmonização de Normas sobre Propriedade Intelectual no MERCOSUL em Matéria de Marcas, Indicações de Procedência e Denominações de Origem (1995), ratificado apenas pelo Paraguai e Uruguai até o momento ${ }^{29}$.

De acordo com a legislação brasileira referente à propriedade industrial, esses instrumentos deveriam ser harmonizados com as legislações em vigor no país. O Poder Executivo deve submeter à aprovação do Congresso Nacional projeto de lei que vise à harmonização das políticas de propriedade industrial entre o Brasil e países integrantes do MERCOSUL ${ }^{30}$.

No contexto do Acordo de Livre Comércio Norte-Americano-NAFTA, há dispositivos sobre a proteção da propriedade intelectual (compreendidos no chamado "Capítulo 17"), com os padrões mínimos de salvaguarda de direitos de titulares no âmbito do bloco. No entanto, o mesmo Acordo, em seu Capítulo 11, prevê a proteção de investimentos intangíveis, como os direitos de propriedade intelectual. Segundo Lahra Liberti:

[...] Como um "investimento", direitos de propriedade intelectual são protegidos na forma de "propriedade intangível" pelo Capítulo 11 do NAFTA, determinando a resolução de disputas entre investidores e Estados, além de permitir a possibilidade de disputas entre Estado, conforme dispõe o Capítulo 20 do mesmo acordo. Com a exceção do acordo de livre comércio entre Estados Unidos e Austrália, que só permite disputas entre Estados, acordos internacionais de investimento geralmente permitem que investidores privados adjudiquem um Estado-Parte diante de um tribunal internacional de arbitragem, caso ocorram violações aos padrões de proteção de direitos de propriedade intelectual. Apenas algumas queixas foram registradas por investidores privados sob a égide do NAFTA e de BITs com relação a violações de direitos de propriedade intelectual. Nenhuma delas foi adjudicada até o momento ${ }^{31}$.

29 MERCOSUL. Protocolo de Armonización de Normas sobre Propiedad Intelectual en el MERCOSUR, en materia de Marcas, Indicaciones de Procedencia y Denominaciones de Orígen. [acesso em 23 de fevereiro de 2015]. Disponível em: <http://www.mre.gov.py/v1/Adjuntos/ mercosur/mercosurprincipal.htm>

30 Art. 242. O Poder Executivo submeterá ao Congresso Nacional projeto de lei destinado a promover, sempre que necessário, a harmonização desta Lei com a política para propriedade industrial adotada pelos demais países integrantes do MERCOSUL. BRASIL. Lei no 9.279, de 14 de maio de 1996. [acesso em 10 de fevereiro de 2015]. Disponível em: <http://www.planalto. gov.br/ccivil_03/leis/19279.htm>

31 Tradução livre do trecho: "[...] As an "investment", IPRs are protected as "intangible property" under NAFTA Chapter 11 providing for investor-state dispute settlement, in addition to the possibility of state-state dispute settlement under NAFTA Chapter 20. Except for the US-Australia FTA, which only provides for state-to-state dispute settlement, international investment agreements generally allow private investors to sue a state party to an investment treaty before an international arbitration tribunal, should a breach of IPR protection standards under the treaty occur. A few claims have been brought by private investors under both NAFTA and BITs on the basis of an alleged violation of IPRs. None of them has been adjudicated so far." LIBERTI, Lahra. Intellectual Property Rights in International Investment 


\section{SOLUCÃO DE CONTROVÉRSIAS EM PROPRIEDADE INTELECTUUAL E INVESTIMENTOS NO ÂMBITO DO NAFTA E DO MERCOSUL}

No sistema multilateral do comércio sob as bases do GATT/OMC, o Órgão de Solução de Controvérsias tem jurisdição para apreciar litígios envolvendo matérias do Acordo TRIPS, em contenciosos nos quais apenas os Membros da Organização são legitimados às reclamações em casos de violação das obrigações multilaterais assumidas. Nos sistemas domésticos, especificamente, os tribunais judiciais têm competência para apreciar ações/demandas ou conceder medidas cautelares relativas às pretensões de titulares em matéria de titularidade e exercício de direitos, validade de registros, atos de violação por terceiros ou mesmo negócios contratuais e licenças. A novidade em termos de estratégia contenciosa, ou mesmo planejamento de estratégias de defesa da propriedade intelectual, encontra-se justamente no recurso à arbitragem internacional de investimentos, envolvendo titulares e Estados receptores $^{32}$.

É importante observar que os acordos de proteção a investimentos e os acordos sobre direitos de propriedade intelectual são regimes muitos distintos, inclusive no que diz respeito aos procedimentos de solução de controvérsias. Com fundamento em obrigações internacionais assumidas em acordos de investimentos, investidores e titulares podem, geralmente, acionar mecanismos de solução de controvérsias para endereçar reclamações contra atos de violação praticados pelo Estado receptor em suas distintas esferas de representação e poderes (órgãos governamentais, agências, legisladores e tribunais judiciais). $\mathrm{Na}$ maioria dos casos, eles recorrem à arbitragem internacional, como bem expressam os procedimentos administrados pelo ICSID ou arbitragem "ad hoc" segundo regras da UNCITRAL.

No caso dos tratados da propriedade intelectual, titulares encontram-se legitimados a buscar a proteção ou tutela jurisdicional em concreto, valendo-se de remédios e medidas judiciais e administrativas disponíveis nos direitos domésticos. Isso porque, segundo as leis internas da propriedade intelectual, o princípio da territorialidade ainda inspira a moldagem dos sistemas nacionais da propriedade intelectual ${ }^{33}$. Da

Agreements: an Overview. In: OECD Working Papers on International Investment, 2010/01, p. 16. [acesso em 23 de fevereiro de 2015]. Disponível em: <http://www.oecd.org/daf/inv/ investment-policy/WP-2010_1.pdf>

32 No caso Eli Lilly/Canadá, por exemplo, o governo canadense publicamente afirmou que a empresa estadunidense havia recorrido aos dispositivos do NAFTA para instituir arbitragem no ICSID, convertida em "tribunal supranacional de apelação", considerando as decisões proferidas no Canadá determinado a nulidade de importantes patentes da companhia. Cf. $<$ http://www.international.gc.ca/trade-agreements-accords-commerciaux/topics-domaines/ disp-diff/eli.aspx?lang=eng>

33 Bom exemplo disso é a fórmula elaborada pelo legislador brasileiro na Lei 9.279/96 
mesma forma, tanto a Convenção de Paris de 1883 como a Convenção de Berna de 1886 e o Acordo TRIPS, asseguram o tratamento nacional para titulares estrangeiros quanto à proteção de seus direitos de propriedade intelectual sobre invenções e criações. Isso significa que os Membros da OMPI e OMC estão obrigados a assegurar o mesmo nível ou grau de proteção aos titulares estrangeiros (nacionais de, ou domiciliados em, outros Membros) que aquele conferido aos seus nacionais ${ }^{34}$.

No contexto do NAFTA, investidores mexicanos, canadenses e estadunidenses passaram, na última década, a demandar judicialmente maior proteção de seus investimentos nos países do bloco. Os Estados Unidos não estavam acostumados a ser acionados em arbitragens internacionais. Isso, passou a ocorrer com mais frequência a partir da inclusão de cláusulas relativas à solução de controvérsias, submetida a procedimentos administrados pelo ICDSID a Corte Permanente de Arbitragem (com referência a arbitragens conduzidas segundo regras da UNCITRAL) $)^{35}$.

Nesse mesmo sentido, os Protocolos de Colônia e de Buenos Aires, do MERCOSUL, ainda que não estejam em vigor, já dispunham de cláusulas que permitiam a investidores a adjudicação de seus direitos também em órgãos como o ICSID e a UNCITRAL:

\section{Protocolo de Colônia, Artigo 9}

1-Toda controvérsia relativa às do presente Protocolo entre um investidor de uma Parte Contratante em cujo território se realizou o investimento será, na medida do possível, resolvida por consultas amistosas.

2-Se a controvérsia não houver sido resolvida no prazo de 6(seis) meses a partir do momento da sua propositura por uma das partes, será submetida, a algum dos seguintes procedimentos, a pedido do investidor: I) ou aos tribunais competentes da Parte Contratante em cujo território se realizou o investimento; ou II) ou à arbitragem internacional, conforme

\footnotetext{
(Código brasileiro da Propriedade Industrial), cujo artigo $2^{\circ}$ assim dispõe: “Art. 20 A proteção dos direitos relativos à propriedade industrial, considerado o seu interesse social e o desenvolvimento tecnológico e econômico do País, efetua-se mediante: I- concessão de patentes de invenção e de modelo de utilidade; II- concessão de registro de desenho industrial; II- concessão de registro de marca; IV- repressão às falsas indicações geográficas; e Vrepressão à concorrência desleal." A regra é lida em conjunto com as cláusulas de abertura ao direito internacional, particularmente aquelas previstas nos artigos $3^{\circ} \mathrm{e} 4^{\circ} \mathrm{da}$ Lei. BRASIL. Lei $\mathrm{n}^{\circ}$ 9.279, de 14 de maio de 1996. [acesso em 10 de fevereiro de 2015]. Disponível em: <http:// www.planalto.gov.br/ccivil_03/leis/19279.htm>

$34 \mathrm{Cf}$. Artigo $5^{\circ}$ da Convenção de Berna de 1886: "Os autores gozam, no que concerne às obras quanto às quais são protegidos por força da presente Convenção, nos países da União, exceto o de origem da obra, dos direitos que as respectivas leis concedem atualmente ou venham a conceder no futuro aos nacionais, assim como dos direitos especialmente concedidos pela presente Convenção".

35 ALVAREZ, Guillermo Aguilar, and PARK, William W. "The New Face of Investment Arbitration: NAFTA Chapter 11". Yale J. Int'l L. 2003, vol 28, no 365, p. 707. [acessado em 18 de fevereiro de 2015]. Disponível em: <http://www.law.yale.edu/documents/pdf/sela/Chapter_ IV-D-2_Investment_Arbitration.pdf >
} 
disposto no parágrafo 4 do presente artigo; ou III) ao sistema permanente de solução de controvérsias com particulares que, eventualmente, venha ser estabelecida no quadro do tratado de Assunção.

3-Quando um investidor tiver optado por submeter a controvérsia a um dos procedimentos estabelecidos no parágrafo 2 do presente artigo, essa escolha será definitiva.

4-No caso de recurso á arbitragem internacional, a controvérsia poderá ser levada, à escolha do investidor: a) ao Centro Internacional de Solução de Controvérsias Relativas a Investimentos (C.I.S.C.I.), criada pela "Convenção sobre Solução de Controvérsias relativas aos Investimentos entre Estados Nacionais de outros Estados", aberto para assinatura em Washington em 18 de março de 1965, quando cada Estado parte do presente Protocolo tenha a ele aderido. Enquanto essa condição não vier a ser cumprida, cada Parte Contratante dará o seu consentimento para que a controvérsia sela submetida a arbitragem em conformidade com o regulamento de Mecanismo Complementar do C.I.S.C.I. para a administração de procedimentos de conciliação, de arbitragem ou de investigação; b) a um tribunal de arbitragem de ad-hoc estabelecido de acordo com as regras de arbitragem da Comissão das Nações Unidas para o Direito Comercial Internacional (UNCITRAL) ${ }^{36}$.

Protocolo de Buenos Aires, Artigo 2, H

1-Qualquer controvérsia relativa a interpretação de um acordo sobre promoção recíproca de investimentos surgida entre um investidor de um Terceiro Estado e um Estado-Parte será, na medida do possível, solucionada por meio de consultas amistosas.

2-Se a controvérsia não puder ser solucionada dentro de um prazo razoável a partir do momento em que for levantada por uma ou outra das partes, poderá ser submetida, por solicitação do investidor: a) ou aos tribunais competentes do Estado-Parte em cujo território foi realizado o investimento; b) ou à arbitragem internacional, nas condições descritas no parágrafo 3. Desde que o investidor tenha submetido a controvérsia à jurisdição do Estado-Parte em litígio ou à arbitragem internacional, a escolha de um ou outro desses procedimentos será definitiva.

3-No caso de recurso à arbitragem internacional, a controvérsia poderá ser submetida, por solicitação do investidor, a um tribunal de arbitragem ad hoc ou a uma instituição internacional de arbitragem.

4-O órgão arbitral decidirá com base nas disposições do acordo assinado, no direito do Estado-Parte envolvido na controvérsia, incluídas as normas relativas a conflitos entre legislações, nos termos de acordos privados eventualmente concluídos relacionados ao investimento e também com

36 MERCOSUL. Protocolo de Colônia para a promoção e proteção recíproca de investimentos no MERCOSUL (intrazona). 17 de janeiro de 1994. [acesso em 18 de fevereiro de 2015]. Disponível em <http://www.cvm.gov.br/port/relinter/MERCOSUL/coloni-p.asp> 
base nos princípios do direito internacional relativos à matéria ${ }^{37}$.

A tendência de se apoiar a proteção dos direitos de propriedade intelectual em mecanismos de proteção de investimentos, como acordos de proteção recíproca ou tratados bilaterais de investimentos parece apontar para um novo paradigma de duplo grau de proteção, em nítida estratégia ofensiva e defensiva por titulares ${ }^{38}$. De um lado, são admitidos outros foros contenciosos para endereçar a reparação em casos de violação de direitos de propriedade intelectual, deslocalizados ou desconectados da jurisdição interna dos estados ou do Órgão de Solução de Controvérsias da OMC, para o TRIPS e Convenções de Berna e de Paris.

Isso é bastante claro nas situações em que a arbitragem de investimentos (ICSID ou ad hoc, segundo regras da UNCITRAL) é adotada para a solução de litígios transnacionais envolvendo direitos de propriedade intelectual. Da mesma forma, os acordos de investimentos têm sido, de modo mais frequente, empregados para questionar a prática de Estados em relação à observância de normas de tratados internacionais da propriedade intelectual ${ }^{39}$. Por essa razão, seria possível mesmo sustentar, também, autêntica estratégia deliberada de de 'forum shopping' envolvendo solução de controvérsias internacionais. Sobre esse movimento, poderíamos certamente falar em transnacionalização dos litígios da propriedade intelectual.

\section{DELINEAMENTOSDOCONTENCIOSOEMPI-INVESTIMENTOS NO CASO PHILIP MORRIS V. URUGUAI}

$\mathrm{Na}$ disputa envolvendo a indústria de tabaco Philip Morris e o Uruguai $^{40}$, em curso no ICSID ${ }^{41}$, o instrumento internacional que dá

37 MERCOSUL. Protocolo sobre promoção e proteção de investimentos provenientes de Estados não-membros do MERCOSUL. 05 de agosto de 1994. [acesso em 23 de fevereiro de 2015]. Disponível em: <http://www.cvm.gov.br/port/relinter/MERCOSUL/buenos-p.asp>

38 Nesse mesmo sentido: "Novas formas de bilateralismo e regionalismo na área de propriedade intelectual simplificam a concepção em torno da apropriação de bens da tecnologia e informação, consolidando interesses dos países desenvolvidos e que não seriam objeto de consenso no multilateralismo clássico da propriedade intelectual sob os sistemas da OMPI e GATT/OMC. POLIDO, Fabrício B. P. Direito internacional da propriedade intelectual: fundamentos, princípios e desafios. Rio de Janeiro: Renovar, 2013, p. 84.

39 GROSSE RUSE-KHAN, Henning. "Litigating Intellectual Property Rights in InvestorState Arbitration: From Plain Packaging to Patent Revocation". In: Fourth Biennial Global Conference of the Society of International Economic Law, SIEL (July 8, 2014). Working Paper. Max Planck Institute for Innovation \& Competition Research. University of Cambridge Faculty of Law, 2014, no 21.

40 INTERNATIONAL CENTRE FOR SETTLEMENT OF INVESTMENT DISPUTES. Philip Morris Brand Sàrl (Switzerland), Philip Morris Products S.A. (Switzerland) and Abal Hermanos S.A. (Uruguay) v. Oriental Republic of Uruguay. Case No. ARB/10/7, March 26, 2010. [acesso em 23 de fevereiro de 2015]. Disponível em: <https://icsid.worldbank.org/apps/ ICSIDWEB/cases/Pages/casedetail.aspx?CaseNo=ARB/10/7\&tab $=$ PRO >

41 INTERNATIONAL CENTRE FOR SETTLEMENT OF INVESTMENT DISPUTES. Philip Morris Brand Sàrl (Switzerland), Philip Morris Products S.A. (Switzerland) and Abal 
suporte à demanda do requerente é um acordo bilateral entre o país sulamericano e a Suíça. Como os Protocolos de Buenos Aires e de Colônia ainda não estão em vigor no MERCOSUL, o embasamento jurídico do caso apoia-se no BIT de $1988^{42}$. O Acordo entre a Confederação Suíça e a República Oriental do Uruguai sobre Promoção e Proteção Recíprocas de Investimentos determina, em seu artigo 10, que eventuais procedimentos de solução de controvérsias poderiam ser adjudicados junto ao ICSID.

Em agosto de 2008, o Ministério da Saúde uruguaio editou regulamento que inclui imagens nas embalagens de cigarros, evidenciando os efeitos adversos decorrentes dos produtos. Além disso, cada empresa estaria obrigada a utilizar marca com mesma forma de apresentação na embalagem de seus diversos produtos, o que dificultaria a comercialização de certas variações (como Malboro Gold, Malboro Blue e Malboro Green). O objetivo das medidas do governo, assim como ocorre em outros países atualmente, é o de reduzir o consumo do cigarro, por razões de proteção à saúde da população.

Com a entrada em vigor dessas medidas, a Philip Morris Products S.A, sociedade anônima constituída de acordo com as leis da Suíça e titular de várias marcas de cigarros comercializadas no Uruguai ("Malboro", "Fiesta", "L\&M", "Philip Morris", “Casino", "Premier", etc.), recorreu aos dispositivos do BIT firmado em 1988. A redução das vendas de cigarros, segundo os produtores, seria reflexo das novas medidas, representado "afronta aos investimentos da empresa" naquele país.

Desde então, o procedimento arbitral conduzido pelo ICSID passou por período de discussão quanto à jurisdição do Centro para a resolução do conflito, solucionada apenas em julho de 2013. Decidiu-se que o ICSID tem jurisdição sobre a demanda apresentada pela Philip Morris. Desde então o procedimento encontra-se em fase preliminar de instauração do processo arbitral, com pedido de participação de "amicus curiae" (Organização Mundial da Saúde) recentemente concedido, em 2015.

Seria, no entanto, esse o foro adequado para a resolução do litígio que envolve não apenas questões de propriedade intelectual, mas também matéria de política de promoção de saúde pública, como é o caso da regulação do conteúdo de embalagens de cigarros? A conformação multilateral do Órgão de Solução de Controvérsias da OMC, com jurisdição para dirimir questões referentes à proteção da propriedade intelectual entre Membros do TRIPS, apresentaria

\footnotetext{
Hermanos S.A. (Uruguay) v. Oriental Republic of Uruguay. Case No. ARB/10/7, March 26, 2010. [acesso em 23 de fevereiro de 2015]. Disponível em: <https://icsid.worldbank.org/apps/ ICSIDWEB/cases/Pages/casedetail.aspx?CaseNo=ARB/10/7\&tab $=$ PRO $>$

42 INTERNATIONAL CENTRE FOR SETTLEMENT OF INVESTMENT DISPUTES. Philip Morris Brand Sàrl (Switzerland), Philip Morris Products S.A. (Switzerland) and Abal Hermanos S.A. (Uruguay) v. Oriental Republic of Uruguay. Case No. ARB/10/7, March 26, 2010, p. 04. [acesso em 23 de fevereiro de 2015]. Disponível em: <https://icsid.worldbank.org/ apps/ICSIDWEB/cases/Pages/casedetail.aspx?CaseNo=ARB/10/7\&tab=PRO>
} 
contexto mais neutro e qualificado de análise dessas questões ${ }^{43}$, caso se entendesse que as medidas adotadas pelo Uruguai violariam obrigações multilaterais ali assumidas, em resposta a qualquer reclamação eventual mente apresentada pela Suíça.

No âmbito do NAFTA, questões de propriedade intelectual e a proteção de investimentos no bloco também foram levantadas, já em 1994, quando representantes da indústria de tabaco nos Estados Unidos apresentaram reclamações contra o governo do Canadá. Para reduzir o consumo do produto no país, o governo canadense iniciou os procedimentos legislativos para uma lei semelhante à do Uruguai, que impunha a necessidade de embalagens padronizadas para cigarros, além de advertências de saúde e a utilização da mesma fonte, independentemente da variedade do produto incorporando determinada marca.

As companhias afirmavam que, de acordo com normas previstas no NAFTA, a medida legislativa adotada pelo Canadá consistiria em expropriação de direitos de propriedade intelectual, passível de compensação.

$\mathrm{O}$ caso restou não submetido à arbitragem de investimentos, pois a legislação atacada foi considerada inconstitucional pela Suprema Corte canadense, por violar direitos de expressão ${ }^{44}$. Em 2001, a própria Philip Morris utilizou argumentos semelhantes para arguir que uma legislação que proibia o uso das palavras "mild" e "light" em embalagens de cigarro feria seus direitos de propriedade intelectual no país.

\footnotetext{
43 Nesse sentido, Carlos M. Correa afirma que: "a proteção de investimento cria áreas cinzentas que podem ser usadas para desafiar medidas no âmbito interno dos países, mesmo que sejam compatíveis com o TRIPS. Ainda que existam bons argumentos para enfrentar essas alegações, há embasamento legal para disputas e para ameaçar com retaliações comerciais países receptores de investimentos. Caso o titular de direitos de propriedade intelectual prevaleça, também haveria espaço para que mecanismos de solução de controvérsias induzam mudanças nas legislações nacionais de propriedade intelectual, para se conformar com as práticas acordadas com o país estrangeiro. Tradução livre do trecho: Investment protection generates grey areas that may be used to challenge national measures, even if they are TRIPSconsistent. Although there are good arguments to counter such challenges, there is legal scope for dispute and for threatening host countries with trade retaliations. Should the IPR title holders prevail, there would also be room for the dispute mechanisms to induce changes of national IPR legislation in host countries to conform to the rights practiced under the agreement." CORREA, Carlos M. Bilateral Investment Agreements: Agents of New Global Standards for the Protection of Intellectual Property Rights? August, 2004, p. 28. [acesso em 21 de fevereiro de 2015]. Disponível em: <file:///Users/lucasanjos/Downloads/grain-125bilateral-investment-agreements-agents-of-new-global-standards-for-the-protection-ofintellectual-property-rights.pdf>

44 LIBERTI, Lahra. Intellectual Property Rights in International Investment Agreements: an Overview. In: OECD Working Papers on International Investment, 2010/01, p. 16. [acesso em 23 de fevereiro de 2015]. Disponível em: <http://www.oecd.org/daf/inv/investment-policy/WP2010_1.pdf>
} 


\section{CONSIDERAÇÕES FINAIS}

A arquitetura dos acordos de investimento, ao incluir cláusulas relativas aos direitos de propriedade intelectual, artificialmente assimilados a ativos passiveis de proteção, tem criado esfera autônoma de jurisdição para a solução de litígios, especificamente, a arbitragem entre Estado e investidor. No sistema internacional da propriedade intelectual, ao lado do recurso aos tribunais, aos órgãos administrativos domésticos e ao Sistema de Solução de Controvérsias da OMC, (para controvérsias decorrentes do Acordo TRIPS e Convenções de Berna e Paris), uma terceira instância contenciosa é, assim, reforçada. Poderse-ia falar em tripla esfera jurisdicional em matéria de propriedade intelectual.

Cada vez mais, direitos de propriedade intelectual e de proteção a investimentos experimentam uma convergência nas pautas da agenda internacional. Seja em decorrência dos interesses privados sobre os quais ambos versam, seja pela proximidade da relação entre proteção aos titulares de direitos de propriedade intelectual e o binômio fomento/ atração de investimentos, observa-se uma cenvergência dessas duas áreas. No entanto, não é certo que a natureza dos bens de propriedade intelectual teria a mesma característica privatista e já assentada no conceito clássico de propriedade dos bens móveis e imóveis tradicionais ou de ativos de investimentos implicados nas relações investidor-Estado.

Existe a necessidade de melhor compreensão sobre a relação finalista e conceitual decorrente dos direitos de propriedade intelectual e as inconsistências em equiparar ou de assimilar essa categoria aos investimentos, objeto de proteção em acordos de proteção recíproca ou tratados bilaterais de investimentos (BITs). A noção de investimentos admitiria uma extensão artificial para justificar a proteção de direitos de propriedade intelectual (e.g direitos de autor, patentes, marcas, desenhos, programas de computador, know how, segredo empresarial).

A alternativa de litigar contra Estados no plano internacional via arbitragem Estado-investidor potencializa o acesso de particulares aos tribunais internacionais, confrontando-se com os modelos clássicos de acesso à jurisdição no Direito Internacional, em que Estados e organizações internacionais (e não indivíduos e empresas) têm legitimidade para propositura de reclamações. O paralelo é estabelecido em relação aos tribunais regionais nos sistemas de proteção internacional dos direitos humanos, como a Corte Europeia de Direitos Humanos, a Corte Interamericana de Direitos Humanos e a Corte Africana de Direitos Humanos.

Considerando que o Protocolo de Colônia e o Protocolo de Buenos Aires ainda não se encontram em vigor no âmbito do MERCOSUL, as opções de judicialização disponíveis para os titulares de direitos de 
propriedade intelectual ainda são aquelas tradicionais, como os tribunais domésticos dos países-membros para entes privados e o Órgão de Solução de Controvérsias da OMC para Estados. No contexto do Nafta e dos demais acordos bilaterais de proteção a investimentos, o cenário é outro, com o reforço jurisdicional de medidas em favor dos titulares privados, que corroboram titularidade, validade, registros, licenças e a caracterização de violação a esses direitos.

Para o caso dos litígios em matéria de investimentos, o recurso a tribunais arbitrais, segundo regras do ICSID e UNCITRAL, significa, tecnicamente, que empresas titulares de direitos de propriedade intelectual não mais dependeriam, única e exclusivamente, de proteção diplomática ou de recurso indireto ao Estado para buscar proteção contra situações envolvendo aquisição, manutenção e exercício dos direitos, como em litígios decorrentes da intepretação e aplicação das convenções clássicas da propriedade intelectual e do TRIPS.

$\mathrm{O}$ recurso à arbitragem internacional de investimentos seria uma dessas alternativas, a partir das quais empresas estrangeiras, na qualidade de investidoras, acionam o Estado receptor em foro arbitral, desvinculado das jurisdições estatais ou do Órgão de Solução de Controvérsias. Considerando o fato de que as disposições dos tratados bilaterais e acordos de proteção recíproca de investimentos abrangem também a propriedade intelectual, esses instrumentos podem oferecer fundamentos normativos não compreendidos no regime do TRIPS, e que autorizem particulares ao recurso à arbitragem contra o Estado, aumentando a litigiosidade dessa temática e subvertendo os instrumentos de proteção consolidados pelo direito internacional da propriedade intelectual.

\section{AGRADECIMENTOS}

Este artigo é resultado de pesquisas desenvolvidas pelos autores no projeto estruturante Estado e Mundialização: Fronteiras do Trabalho e Tecnologias, vinculado à Linha de Pesquisa Poder, História e Liberdade, do Programa de Pós-Graduação em Direito, da Universidade Federal de Minas Gerais, e do Grupo Estado, Relações Privadas Transnacionais nas Fronteiras da Tecnologia e Inovação, do Departamento de Direito Público da UFMG. Pelos incentivos ao desenvolvimento da investigação na área de Direito Internacional da Propriedade Intelectual, os autores agradecem ao apoio institucional da Pró-Reitoria de Pesquisa da Universidade Federal de Minas Gerais (Edital no 01/2013). 


\section{REFERÊNCIAS BIBLIOGRÁFICAS}

ALVAREZ, Guillermo Aguilar, and PARK, William W. “The New Face of Investment Arbitration: NAFTA Chapter 11". Yale J. Int'l L. 2003. vol 28, $\mathrm{n}^{\circ}$ 365. [acessado em 18 de fevereiro de 2015]. Disponível em: $<$ http:// www.law.yale.edu/documents/pdf/sela/Chapter_IV-D-2_Investment_ Arbitration.pdf>

ANZORENA, C. Ignacio Suarez; PERRY, William K. "The Rise of Bilateral Investment Treaties". In: House Defense Quaterly, Summer 2010. [acesso em 23 de fevereiro de 2015]. Disponível em: <http:// www.chadbourne.com/files/Publication/f1898f01-febc-4fba-bb9487ff36d1b1a2/Presentation/PublicationAttachment/8c6065d3-c22f4a1e-a187-8c94079e98bc/IDQ-2010-03-SuarezAnzorenaPerry.pdf>

BRASIL. Decreto $n^{\circ}$ 75.699, de 6 de maio de 1975. [acesso em 9 de março de 2015]. Disponível em: <http://www.planalto.gov.br/ccivil_03/ decreto/1970-1979/D75699.htm>

BRASIL. Decreto $n^{\circ}$ 75.572, de 8 de abril de 1975. [acesso em 9 de março de 2015]. Disponível em: <http://www.planalto.gov.br/ccivil_03/ decreto/1990-1994/D0635.htm>

BRASIL. Lei $n^{\circ}$ 9.279, de 14 de maio de 1996. [acesso em 10 de fevereiro de 2015]. Disponível em: <http://www.planalto.gov.br/ccivil_03/leis/ 19279.htm>

CORREA, Carlos M. Bilateral Investment Agreements: Agents of New Global Standards for the Protection of Intellectual Property Rights? August, 2004. [acesso em 21 de fevereiro de 2015]. Disponível em: <tile:///Users/ lucasanjos/Downloads/grain-125-bilateral-investment-agreementsagents-of-new-global-standards-for-the-protection-of-intellectualproperty-rights.pdf>

COSTA, José Augusto Fontoura. "Proteção e promoção do investimento estrangeiro no MERCOSUL uma ferramenta para a implementação de um bom clima de investimentos?". Revista Brasileira de Política Internacional. 2006, vol 49, $\mathrm{n}^{\circ} 2$ [acesso em 11 de março de 2015]. Disponível em: <http://www.scielo.br/scielo.php? script=sci_ arttext\&pid=S0034-73292006000200004\&lng=en\&nrm=iso $>$

EUROPEAN COMISSION. Investment Protection and Investor-to-State Dispute Settlement in EU Agreements. [acesso em 18 de fevereiro de 2015]. Disponível em: <http://trade.ec.europa.eu/doclib/docs/2013/ november/tradoc_151916.pdf $>$

EUROPEAN COMISSION. The EU's bilateral trade and investment agréments: where are we? [acesso em 18 de fevereiro de 2015]. Disponível em: <http://trade.ec.europa.eu/doclib/docs/2012/november/ tradoc_150129.pdf $>$

GROSSE RUSE-KHAN, Henning. "Litigating Intellectual Property Rights in Investor-State Arbitration: From Plain Packaging to Patent 
Revocation". In: Fourth Biennial Global Conference of the Society of International Economic Law, SIEL (July 8, 2014). Working Paper. Max Planck Institute for Innovation \& Competition Research. University of Cambridge Faculty of Law, 2014, nº 21.

INTERNATIONAL CENTRE FOR SETTLEMENT OF INVESTMENT DISPUTES. Convention on the Settlement of Investment Disputed Between States and Nationals of Other States, October 15, 1966 [acesso em 9 de fevereiro de 2015]. Disponível em: <https://icsid.worldbank.org/apps/ ICSIDWEB/icsiddocs/Documents/ICSID\%20Convention\%20English. pdf $>$

INTERNATIONAL CENTRE FOR SETTLEMENT OF INVESTMENT DISPUTES. Philip Morris Brand Sàrl (Switzerland), Philip Morris Products S.A. (Switzerland) and Abal Hermanos S.A. (Uruquay) v. Oriental Republic of Uruguay. Case No. ARB/10/7, March 26, 2010 [acesso em 23 de fevereiro de 2015]. Disponível em: <https:// icsid.worldbank.org/apps/ICSIDWEB/cases/Pages/casedetail. aspx?CaseNo $=\mathrm{ARB} / 10 / 7 \& \mathrm{tab}=\mathrm{PRO}>$

JUNIOR, Umberto Celli. "O impacto dos acordos de investimentos sobre os Estados-Membros do MERCOSUL". Cadernos Prolam/USP. 2005, vol 4, no 6 [acesso em 21 de fevereiro de 2015]. Disponível em: <http://www.revistas.usp.br/prolam/article/view/81786/85094>

LIBERTI, Lahra. "Intellectual Property Rights in International Investment Agreements: an Overview". OECD Working Papers on International Investment. [acesso em 23 de fevereiro de 2015]. Disponível em: <http://www.oecd.org/daf/inv/investment-policy/WP-2010_1.pdf>

KLOPSCHINSKI, Simon. Der Schutz geistigen Eigentums durch völkerrechtliche Investitionsverträge. Berlin: ${ }^{\mathrm{C}}$. Heymanns, 2011.

MERCOSUL. Estado de ratificaciones y vigências de tratados y protocolos del Mercosur y Estados asociados. [acesso em 23 de fevereiro de 2015]. Disponível em: <http://www.mre.gov.py/v1/Adjuntos/mercosur/ mercosurprincipal.htm>

MERCOSUL. Protocolo de Armonización de Normas sobre Propiedad Intelectual en el MERCOSUR, en materia de Marcas, Indicaciones de Procedencia y Denominaciones de Orígen. [acesso em 23 de fevereiro de 2015]. Disponível em: <http://www.mre.gov.py/v1/Adjuntos/mercosur/ mercosurprincipal.htm $>$

MERCOSUL. Protocolo de Colônia para a promoção e proteção recíproca de investimentos no MERCOSUL (intrazona). I7 de janeiro de 1994. [acesso em 18 de fevereiro de 2015]. Disponível em: $<$ http://www.cvm. gov.br/port/relinter/MERCOSUL/coloni-p.asp>

MERCOSUL. Protocolo sobre promoção e proteção de investimentos provenientes de Estados não-membros do MERCOSUL. 05 de agosto de 1994. [acesso em 23 de fevereiro de 2015]. Disponível em: <http://www. cvm.gov.br/port/relinter/MERCOSUL/buenos-p.asp> 
MERCURIO, Bryan. "Awakening the Sleeping Giant: "Intellectual Property Rights in International Investment Agreements". Journal of International Economic Law. 2012, vol 15, n³.

MERGES, Robert P. Justifying intellectual property. s.n: Harvard University Press, 2011, p. 292. [acesso em 11 de março de 2015]. Disponível em: <http://denning.law.ox.ac.uk/news/events_files/JIP_-Chapter_10_-_Conclusion_-_June_2011.pdf $>$

NAFTA. North American Free Trade Agreement. 10 de janeiro de 1994. [acesso em 18 de fevereiro de 2015]. Disponível em: <https://www. nafta-sec-alena.org/Home/Legal-Texts/North-American-Free-TradeAgreement>

NEWFARMER, Richard. Regional Trade Agreements: Designs for Development. Trade, Doha and Development: a Window into the Issues. The International Bank for Reconstruction and Development, November 2005. [acesso em 22 de fevereiro de 2015]. Disponível em: <http:// citeseerx.ist.psu.edu/viewdoc/download?doi=10.1.1.458.3724\&rep=rep $1 \&$ type $=$ pdf\#page $=292>$

PERMANENT COURT OF ARBITRATION. UNCITRAL Arbitration Rules and the PCA. [acesso em 10 de fevereiro de 2015]. Disponível em: $<$ http://www.pca-cpa.org/showpage.asp?pag_id=1061>

POLIDO, Fabrício B. P. Direito internacional da propriedade intelectual: fundamentos, princípios e desafios. Rio de Janeiro: Renovar, 2013.

SELL, Susan K. Cat and Mouse: Industries', States' and NGOs' Forum Shifting in the Battle Over Intellectual Property Enforcement. September 1,2009. [acesso em 23 de fevereiro de 2015]. Disponível em: $<$ http://ssrn. com/abstract $=1466156>$ or $<$ http://dx.doi.org/10.2139/ssrn.1466156>

SIMMA, Bruno; PULKOWSKI, Dirk. "Of planets and the universe: self-contained regimes in international law". European Journal of International Law. 2006, vol 17, no 3, p. 483-529.

TEUBNER, Gunther; FISCHER-LESCANO, Andreas. "Regimecollisions: the vain search for legal unity in the fragmentation of global law". Michigan Journal of International Law. 2004, vol 25, n' 4, p. 999 1046.

TORRES, Igor Gonçalves. "Acordos de livre comércio, desnacionalização e sistemas financeiros : os casos do Brasil, Chile e México". [Tese de Doutorado em História]. Brasília: Universidade de Brasília, 2006. p. 94. [acesso em 11 de março de 2015]. Disponível em: <http://repositorio. unb.br/bitstream/10482/7615/1/2006_igor_torres.pdf>

WORLD TRADE ORGANIZATION. Agreement on Trade-Related Aspects of Intellectual Property Rights. April 15, 1994. [acesso em 23 de fevereiro de 2015]. Disponível em: <https://www.wto.org/english/ tratop_e/trips_e/t_agm0_e.htm> 